\title{
Morphometric analysis of the mandible in the Durban Metropolitan population of South Africa
}

\author{
S. Ishwarkumar, P. Pillay, M.R. Haffajee, K.S. Satyapal \\ Department of Clinical Anatomy, School of Laboratory Medicine and Medical Sciences, College of Health Sciences, \\ University of KwaZulu-Natal, Westville Campus, Durban, South Africa
}

[Received: 13 July 2015; Accepted: 3 September 2015]

\begin{abstract}
Background: The identification of an individual from skeletal remains plays a vital role in forensic investigation as it is essential for the identification of the individual's age, sex, and/or race and further analysis. Skeletal characteristics differ from one population group to another since population-specific osteometric standards exist for sex determination. Since the mandible is the largest, strongest and most durable compact facial bone, it is the best preserved after death. While sexual dimorphism of the mandible is indicated by its shape and size, morphometric analysis is more accurate in the determination of sex from the skull. The aim of this study was to evaluate the morphometric parameters of the mandible in the Durban Metropolitan population.

Materials and methods: Various morphometric parameters of the mandible were measured and assessed in 265 digital panoramic radiographs aged between 16 and 30 years $(n=530)$. Each parameter recorded was statistically analysed using SPSS to determine if a relationship existed between the parameter, and sex and age. Results: In this study the morphometric parameters of the male mandibles were greater than that of the females. This concurred with the findings of previous studies. The length of the mandibular ramus on the right and left sides was statistically significant with sex.

Conclusions: This correlated with previous studies, indicating that the length of the mandibular ramus generally has higher sexual dimorphism than any other morphometric mandibular parameter $(p=0.000)$. However, only the length of the right mandibular body was statistically significant when compared with sex ( $p$ $=0.040$ ). The findings of this study may assist forensic investigators, anatomists, anthropologists and maxillo-facial surgeons. (Folia Morphol 2017; 76, 1: 82-86)
\end{abstract}

Key words: mandible, morphometry, radiology, mandibular body, mandibular ramus

\section{INTRODUCTION}

Indira et al. [6] stated that the identification of an individual from skeletal remains plays a critical role in forensic investigation and is essential for the identification of age, sex and race, as well as further analysis. Since age and stature are dependent on the sex of the individual, sex determination is considered to be the primary step in the identification of skeletal remains [6].

Unidentified skeletal remains in South Africa are currently classified according to the Northern hemispheric standards [7]. However, a study conducted within the white and black population groups native

Address for correspondence: Prof. K.S. Satyapal, Department of Clinical Anatomy, School of Laboratory Medicine and Medical Sciences, College of Health Sciences, University of KwaZulu-Natal, Westville Campus, Private Bag X54001, Durban, 4000, South Africa, tel: + 27312607110 , fax: + 2731260 7890, e-mail: satyapalk@ukzn.ac.za 


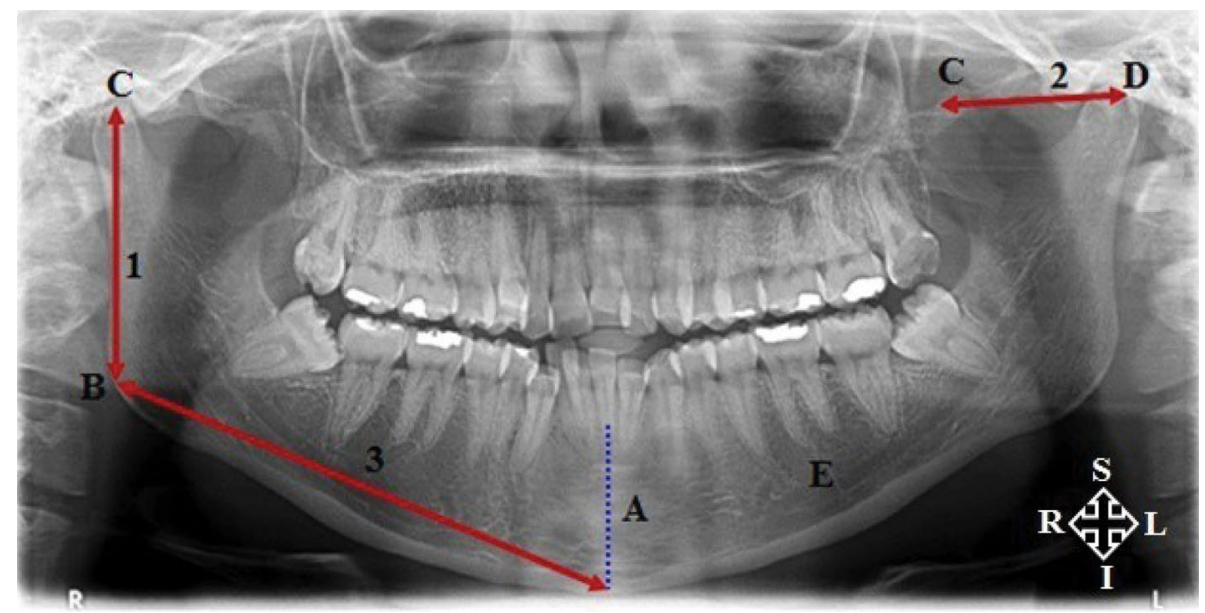

Figure 1. Measurements of the mandible on a panoramic $\mathrm{X}$-ray of the jaw; $\mathrm{A}$ - mental protuberance; $\mathrm{B}$ - angle of the mandible; $\mathrm{C}-$ head of the mandible; $\mathrm{D}$ - coronoid process of the mandible; $\mathrm{E}$ - body of the mandible; I - inferior; $\mathrm{L}$ - left; $\mathrm{S}$ - superior; $\mathrm{R}$ - right; 1 length of the ramus; 2 - width of the ramus; 3 - length of the body.

to South Africa showed that differences exist in the craniometric parameters when compared to the North American standards [7]. Iscan and Steyn [7] reported that "Prediction accuracy was considerably lower when North American-based formulae were tested on the South African population, indicating distinct craniometric differences between these populations." Although, Indira et al. [6] reported that the sexual dimorphism of the mandible is indicated by its shape and size, morphometric mandibular analysis also proves to be accurate for the determination of sex.

As revealed by the recovered paleo-anthropological hominid specimens, the strength and durability of the mandible enables it to be best preserved after death $[6,13]$.

Therefore, the aim of this study was to evaluate the morphometric parameters of the mandible in the Durban Metropolitan population.

\section{MATERIALS AND METHODS}

Two hundred and sixty-five (124 males; $141 \mathrm{fe}-$ males) digital panoramic radiographs of South African Indian patients aged between 16 and 30 years were studied using the digital Kodak Dental Imaging Software (Version 6.12.17.0). The radiographs were obtained from the Radiology Departments of private dental practices in the Greater Durban Metropolitan area. Ethical clearance was obtained (BE.410/13).

The selection criteria were:

- Inclusion:

- panoramic radiographs of patients between 16 and 30 years of age that showed no history of trauma and had complete patient records;
- patients belonging to the Indian race group within the KwaZulu-Natal region.

- Exclusion:

- panoramic radiographs of patients below 16 and above 30 years of age;

- poor quality radiographs;

- patients showing any fracture of the jaws.

\section{Morphometric analysis}

The mandibular size was measured between two chosen points using the mouse-drive method adopted by Indira et al. [6]:

- the length of the ramus of the mandible was recorded from the angle of the mandible to the head of the mandible (B to C) (Fig. 1; see '1');

- the width of the ramus was measured from the head of the mandible to the coronoid process (C to D) (Fig. 1; see '2');

- the length of the body of the mandible was recorded from the mental protuberance to the angle of the mandible ( $A$ to $B$ ) (Fig. 1; see ' 3 ').

\section{Statistical analysis}

The comparison between age, sex and the data pertaining to the mandibular size was performed using the Statistical Package for Social Sciences (SPSS version 21.0). The Pearson $\chi^{2}$ test and Independent Samples T-test were used to analyse the relationship between age, sex and morphometry of the mandible. A p-value of less than 0.05 was considered to be statistically significant. The reliability and validity of this study was maintained by measuring each morphometric parameter three times and an average was calculated, recorded and analysed. 
Table 1. Morphometric analysis of the mandible with sex distribution

\begin{tabular}{|c|c|c|c|c|c|c|}
\hline \multirow[t]{2}{*}{ Parameters } & \multirow[t]{2}{*}{ Side } & \multicolumn{3}{|c|}{ Measurements [mm] } & \multicolumn{2}{|c|}{$\mathbf{P}$} \\
\hline & & Males & Females & Both & Sex & Age \\
\hline \multirow[t]{2}{*}{ Length of ramus } & Right & 59.6 & 53.9 & 56.5 & $0.000^{*}$ & 0.111 \\
\hline & Left & 60.1 & 54.3 & 57.0 & $0.000^{*}$ & 0.153 \\
\hline \multirow[t]{2}{*}{ Width of ramus } & Right & 36.0 & 35.5 & 35.8 & 0.625 & 0.537 \\
\hline & Left & 35.1 & 34.2 & 34.6 & 0.414 & 0.479 \\
\hline \multirow[t]{2}{*}{ Length of body } & Right & 86.5 & 83.0 & 84.6 & $0.040^{*}$ & 0.799 \\
\hline & Left & 83.3 & 81.0 & 82.0 & 0.147 & 0.0735 \\
\hline
\end{tabular}

${ }^{*}$ Statistically significant $(p<0.05)$

Table 2. Length of the mandibular ramus in males and females

\begin{tabular}{lccc}
\hline Author [year] & Population & \multicolumn{2}{c}{$\begin{array}{c}\text { Length } \\
\text { of mandibular } \\
\text { ramus [mm] }\end{array}$} \\
\cline { 3 - 4 } & & Male & Female \\
\hline Burstone et al. (1978) & American & 52.0 & 46.8 \\
Mbajiorgu et al. (1996) & Zimbabwean & 61.3 & 59.8 \\
Fabian and Mpembeni (2002) & Tanzanian & 49.9 & 44.2 \\
Rai et al. (2007) & Indian & 53.9 & 51.8 \\
Keyayan et al. (2011) & Kenyan & 57.7 & 52.0 \\
Shamout et al. (2012) & Jordanian & 53.2 & 49.1 \\
Yassir (2013) & Iraqi & 51.4 & 45.1 \\
Present study (2014) & South African & 59.9 & 54.1 \\
\hline
\end{tabular}

\section{RESULTS}

\section{Length of the mandibular ramus}

The length of the mandibular ramus was longer on the left side in both males and females, with mean lengths of $57.0 \mathrm{~mm}$ and $56.5 \mathrm{~mm}$ recorded on right and left sides, respectively (Table 1 ). The length of the male mandibular ramus was longer than that of the female on both sides (Table 1). In addition, a statistically significant correlation was recorded for the length of the mandibular ramus and sex between right and left sides $(p=0.000)$.

\section{Width of the mandibular ramus}

The width of the mandibular ramus was greater in males than females on both right and left sides (Table 1). The width of the right mandibular ramus was identified to be greater than the left in both males and females, with mean widths of $35.8 \mathrm{~mm}$ and $34.6 \mathrm{~mm}$ on right and left sides, respectively. There was no significant difference in the width of the mandibular ramus between the two sexes (Table 1 ).

\section{Length of the mandibular body}

The length of the right mandibular body was longer than the left side in both males and females, with mean lengths of $84.6 \mathrm{~mm}$ and $82.0 \mathrm{~mm}$, respectively (Table 1). In addition, the length of the mandibular body was longer in males than females on both sides. The comparison of the length of the right mandibular body with sex displayed a statistically significant difference $(p=0.040)$ (Table 1$)$.

\section{DISCUSSION}

The accurate identification of human remains is essential in forensic medicine and anthropology, especially during criminal investigation and in the identification of accident or natural disaster victims $[1,6]$. Racial, genetic and regional differences in functional activity of the mandible during the early stages of growth and development may affect its shape and size [14]. Consequently, the skeletal characteristics differ from one population group to another as population-specific osteometric standards exist for sex determination $[6,16,21]$. According to Indira et al. [6], there is paucity in the literature regarding the determination of mandibular morphometry through the use of digital panoramic radiographs [6].

The morphometric parameters in this study were found to be greater in male mandibles and this corroborated the results of Duthie et al. [3] and Indira et al. [6] as male bones are generally bigger and more robust.

\section{Length of the mandibular ramus}

The length of the right mandibular body was longer than the left in both males and females and a statistically significant relationship between the length of the mandibular ramus and sex was recorded on both sides of the mandible in this study $(p=0.000)$ (Table 2$)$. The results of the current study confirmed that of previous 
Table 3. Width of the mandibular ramus in males and females

\begin{tabular}{lccc}
\hline Author (year) & Population & \multicolumn{2}{c}{$\begin{array}{c}\text { Width } \\
\text { of mandibular } \\
\text { ramus [mm] }\end{array}$} \\
\cline { 3 - 4 } & & Male & Female \\
\hline Suzuki and Takahashi (1975) & Japanese & 32.9 & 31.9 \\
Ranganath et al. (2008) & Indian & 38.8 & 40.7 \\
Vinay and MangalaGowri & Indian & 41.7 & 38.9 \\
(2013) & & & \\
Present study (2014) & South African & 35.6 & 34.9 \\
\hline
\end{tabular}

Table 4. Length of the mandibular body in males and females

\begin{tabular}{lccc}
\hline Author (year) & Population & \multicolumn{2}{c}{$\begin{array}{c}\text { Length } \\
\text { of mandibular } \\
\text { body [mm] }\end{array}$} \\
\cline { 3 - 4 } & & Male & Female \\
\hline Mbajiorgu et al. (1996) & Zimbabwean & 77.8 & 72.3 \\
Jayakaran et al. (2000) & Indian & 74.4 & 70.6 \\
Onngkana et al. (2009) & Thai & 89.4 & 85.3 \\
Keyayan et al. (2011) & Kenyan & 99.8 & 93.4 \\
Vinay and MangalaGowri & Indian & 75.4 & 72.5 \\
(2013) & & & \\
Yassir (2013) & Iraqi & 74.9 & 69.9 \\
Present study (2014) & South African & 84.9 & 82.0 \\
\hline
\end{tabular}

studies $[2,4,9,11,14,17,23]$, as the afore-mentioned authors reported the length of the mandibular ramus to be longer in males than in females (Table 2). In addition, Rai et al. [14] and Indira et al. [6] stated that the length of the mandibular ramus generally showed a higher sexual dimorphism than any other mandibular morphometric parameters. It is evident that morphometric differences in the mandible exist between the northern and southern hemispheres as South Africa and Zimbabwe identified longer mandibular rami than countries in the northern hemisphere (America, Iraq and India) (Table 2).This also confirmed the findings of Iscan and Steyn [7] who documented a difference in the craniometric dimensions between South African and North American populations.

\section{Width of the mandibular ramus}

The width of the mandibular ramus in this study was greater in males than females which corroborated the findings of Vinay and MangalaGowri [19]. Conversely, Ranganath et al. [15] found that the mandibular ramus was longer in females (Table 3 ). Although no statistically significant relationship with age or sex was reported in this study $(p>0.05)$ the result compared favourably with the findings of Rai et al. [14]. However, the afore-mentioned authors did not provide an explanation for their findings. In this study, the mean width of the mandibular ramus was considerably less than that recorded by Rai et al. [14] and Vinay and MangalaGowri [19], but greater than that of the Japanese population as reported by Suzuki and Takahashi [18] (Table 3).

\section{Length of the mandibular body}

The length of the male mandibular body in this study was longer than the female and this concurred with previous studies [8, 9, 11, 12, 20, 23] (Table 4). The mean length of the mandibular body in the current study was longer than the Indian [8, 20, 23]; Iraqi [23] and Zimbabwean populations [11]. However, it was smaller than the Kenyan [9] and Thai [12] population groups (Table 4). The afore-mentioned data suggested that differences not only exist between the northern and southern hemispheres but also within the hemispheres and may be a result of populationspecific differences. Only the relationship between the length of the right mandibular body and sex displayed a statistically significant difference in this study $(p=0.040)$. There appeared to be paucity in the literature regarding this particular relationship. In this regard, Luca et al. [10] proposed that mastication and dietary habits may influence the growth of the mandible. They recorded that individuals who consumed an abrasive diet had larger jaws in comparison to those that had a soft diet. In addition, Weiner [22] reported that individuals tend to favour either their right or left side; therefore, this study may suggest that individuals tend to favour chewing on their right side.

Consequently, Humphrey et al. [5] stated that almost any site of mandibular bone deposition, resorption, or remodelling has the potential to become sexually dimorphic, therefore the mandibular condyle and ramus present as the specific sites associated with the greatest morphological changes in size and remodelling during growth. In addition, Indira et al. [6] stated that the development of the muscles of mastication may influence the sexual dimorphism of the mandibular ramus as the masticatory forces exerted differ between the sexes.

\section{CONCLUSIONS}

All morphometric parameters recorded in this study were greater in males than in females. Further- 
more, the present study documented differences in the morphometric parameters between the southern (specifically Durban, South Africa) and northern hemispheric populations. The provision of morphometric data relating to the mandible may assist forensic investigators, anatomists, anthropologists and maxillofacial surgeons, as this may be useful in providing anthropological and surgical data that may be used in medico-legal and dental procedures.

\section{REFERENCES}

1. Akhlaghi M, Moradi B, Hajibeygi M. Sex determination using anthropometric dimensions of the clavicle in Iranian population. J Forensic Leg Med. 2012; 19(7): 381-385, doi: 10.1016/j.jflm.2012.02.016, indexed in Pubmed: 22920759.

2. Burstone $\mathrm{CJ}$, James RB, Legan $\mathrm{H}$, et al. Cephalometrics for orthognathic surgery. J Oral Surg. 1978; 36(4): 269-277, indexed in Pubmed: 273073.

3. Duthie J, Bharwani $\mathrm{D}$, Tallents $\mathrm{RH}$, et al. A longitudinal study of normal asymmetric mandibular growth and its relationship to skeletal maturation. Am J Orthod Dentofacial Orthop. 2007; 132(2): 179-184, doi: 10.1016/j. ajodo.2005.07.032, indexed in Pubmed: 17693367.

4. Fabian FM, Mpembeni R. Sexual dimorphism in the mandible of a homogenous black population of Tanzania. Tanzania J Sci. 2002; 28: 47-54.

5. Humphrey LT, Dean MC, Stringer CB. Morphological variation in great ape and modern human mandibles. J Anat. 1999; 195 (Pt 4): 491-513, doi:10.1046/j.14697580.1999.19540491.x, indexed in Pubmed: 10634689.

6. Indira AP, Markande A, David MP. Mandibular ramus: An indicator for sex determination - A digital radiographic study. J Forensic Dent Sci. 2012; 4(2): 58-62, doi: 10.4103/0975-1475.109885, indexed in Pubmed: 23741142.

7. Işcan MY, Steyn M. Craniometric determination of population affinity in South Africans. Int J Legal Med. 1999; 112(2): 91-97, indexed in Pubmed: 10048665.

8. Jayakaran F, Rajangam S, Janakiram S, et al. Sexing of the mandible. Anatomica Karnataka. 2000; 1: 11-16.

9. Keyayan AO, Chinclia ML, Hassan A, et al. Morphometric parameters of Keyan adult mandibles. East Africa Med J. 2011; 88: 349-355.

10. Luca L, Roberto D, Francesca SM, et al. Consistency of diet and its effects on mandibular morphogenesis in the young rat. Prog Orthod. 2003; 4: 3-7, doi: 10.1034/j.1600-9975.2002.02033.x, indexed in Pubmed: 12887573.

11. Mbajiorgu FE, Zivanovic $S$, Asala $S A$, et al. A pilot study of the mandibular angle in black Zimbabweans. Cent Afr J Med. 1996; 42(10): 285-287, indexed in Pubmed: 9130402.

12. Onngkana N, Paivan S. Gender differences in Thai mandibles using metric analysis. Chiang Mai Med J. 2009; 48: 43-48.

13. Palli TJ, Devi TS, Devi CKL. Studies on human mandible. IOSR J Dental Med Sci. 2014; 13: 8-15.

14. Rai R, Ranade A, Prabhu L, et al. A Pilot Study of the Mandibular Angle and Ramus in Indian Population. Int J Morphol. 2007; 25(2), doi: 10.4067/s071795022007000200019.

15. Ranganath V, Ravindranath Y, Ravindranath R. Sexual dimorphism in mandibular morphology: a study on South Indian sample. South Asian Anthropologist. 2008; 8: 9-11.

16. Saini V, Srivastava R, Rai RK, et al. Mandibular ramus: an indicator for sex in fragmentary mandible. J Forensic Sci. 2011; 56 Suppl 1: S13-S16, doi:10.1111/j.15564029.2010.01599.x, indexed in Pubmed: 20950321.

17. Shamout AR, Ammoush M, Alrbato R, Habahbah AA. Age and gender differences in gonial angle, ramus height and bigonial width in dentate subjects. Pakistan Oral Dental J. 2012; 32: 81-87.

18. Suzuki M, Takahashi Y. Anthropological studies on the mandible of the recent Chubu Japanese. J Anthrop Soc Nippon. 1975; 83(4): 320-329.

19. Vinay G, MangalaGowri SR. Determination of gender by the anthropometric measurements of human mandible using ramus breadth and mandibular angle: a cross sectional study from South India. J Med Sci. 2013; 1: 28-32.

20. Vinay G, MangalaGowri SR, Anbalagan J. Sex determination of human mandible using metrical parameters. J Clin Diagn Res. 2013; 7(12): 2671-2673, doi:10.7860/JCDR/2013/7621.3728, indexed in Pubmed: 24551607.

21. Vondanovic M, Dumancic J, Demo Z, et al. Determination of sex by discriminate function analysis of mandibles from two Croatian archaeological sites. Acta Stomatol Croat. 2006; 40: 263-277.

22. Weiner R. Chew on this: is there a dominant side for chewing? J Mass Dent Soc. 2001; 50(2): 36-38, indexed in Pubmed: 11494464.

23. Yassir A. Ramus height and its relationship with skeletal and dental measurements. J Oral Res. 2013; 1: 2-5. 